\title{
A fingerprint matching algorithm using bit-plane extraction method with phase-only correlation
}

\section{Florence Francis-Lothai and David B.L. Bong*}

Faculty of Engineering,

Universiti Malaysia Sarawak,

Kota Samarahan, Malaysia

Email: nce_1005@yahoo.com

Email: bbldavid@unimas.my

*Corresponding author

\begin{abstract}
This paper introduces a new method in fingerprint feature extraction based on bit-plane. A bit-plane image requires smaller storage space than a greyscale image. Region of interest (ROI) of a fingerprint image is extracted by using a modified blob analysis method, and then the core point of the ROI is detected for dimension reduction process. Before bit-plane is extracted, the fingerprint image is enhanced by using Fourier transform. Bit-plane 7 of the enhanced image is used as the input for fingerprint matching with phase-only correlation (POC) function. Experiment results showed that the storage space requirement for a fingerprint database could be reduced up to $87 \%$ per image for a bit-plane image compared with a greyscale image. The proposed fingerprint matching algorithm achieves $81.16 \%$ of recognition rate on FVC2002-Dbla database and $89.78 \%$ on FingerDOS database.
\end{abstract}

Keywords: bit-plane; biometric; feature extraction; fingerprint matching algorithm; phase-only correlation; POC.

Reference to this paper should be made as follows: Francis-Lothai, F. and Bong, D.B.L. (2017) 'A fingerprint matching algorithm using bit-plane extraction method with phase-only correlation', Int. J. Biometrics, Vol. 9, No. 1, pp.44-66.

Biographical notes: Florence Francis-Lothai received her Master of Electronics Engineering degree from Universiti Malaysia Sarawak in 2016 and Bachelor of Electronic and Computer Engineering degree from Universiti Malaysia Sarawak in 2011. Her research interests include biometric identification, image processing and computer vision.

David B.L. Bong received his $\mathrm{PhD}$ degree from Universiti Sains Malaysia, MSc degree from Nanyang Technological University, Singapore and BEng degree from Universiti Teknologi Malaysia. He is currently a Senior Lecturer with the Faculty of Engineering, Universiti Malaysia Sarawak. His research interests include biometric identification, image quality assessment, feature extraction, computer vision, medical imaging and intelligent systems.

This paper is a revised and expanded version of a paper entitled 'An analysis of the effects of bit plane extraction in fingerprint recognition', presented at IEEE Conference on Systems, Process and Control (ICSPC), Kuala Lumpur, December 12, 2014. 